\title{
Quantitative Correlation of Helicobacter pylori Stool Antigen (HpSA) Test with the Severity of H. pylori-Related Gastritis
}

\author{
Ali K. Adiloglu, ${ }^{1}$ Mehmet Isler, ${ }^{2}$ Ibrahim Goren, ${ }^{2}$ Ozden Candir, ${ }^{3}$ \\ Altug Senol, ${ }^{2}$ Suleyman Onal ${ }^{1}$ and Nermin Karahan ${ }^{3}$ \\ ${ }^{1}$ Department of Medical Microbiology, Suleyman Demirel University, Faculty of Medicine, \\ Isparta, Turkey \\ ${ }^{2}$ Department of Gastroenterology, Suleyman Demirel University, Faculty of Medicine, Isparta, \\ Turkey \\ ${ }^{3}$ Department of Pathology, Suleyman Demirel University, Faculty of Medicine, Isparta, Turkey
}

Adiloglu, A.K., Isler, M., Goren, I., Candir, O., Senol, A., Onal, S. and Karahan, N. Quantitative Correlation of Helicobacter pylori Stool Antigen (HpSA) Test with the Severity of H. pylori-Related Gastritis. Tohoku J. Exp. Med., 2007, 212 (2), 159-167 — The Helicobacter pylori ( $H$. pylori) load in both stomach and stool and the resulting severity of gastritis are important criteria in validating the status of $H$. pylori infection. We aimed to assess the reliability of the $H$. pylori stool antigen (HpSA) test for the primary diagnosis of $H$. pylori infection by calculating the best cut-off value to obtain the highest sensitivity and specificity in dyspeptic patients. We also investigated the correlation of HpSA test with the severity of gastritis and $H$. pylori load. The H. pylori statuses of 95 patients were evaluated by the positivity of both rapid urease test and microscopic detection of $H$. pylori in biopsy specimens, 88 subjects of whom were $H$. pylori positive. The sensitivity and specificity of the HpSA test were $51.1 \%$ (45/88) and 100\% (7/7), respectively, according to the manufacturer's recommended cut-off value of 0.16 . However, with the best cut-off value of 0.048 , calculated by receiver operator characteristics analysis, the sensitivity of the test increased to $92.0 \%(81 / 88)$ with the same specificity. High values of the HpSA test were correlated with high scores of corpus $H$. pylori load and the severity of antrum and corpus inflammation $(p<0.05)$. With the best cut-off value of the HpSA test, the primary diagnosis of $H$. pylori infection can be made with higher sensitivity and specificity. The HpSA test is a helpful tool that evaluates the severity of $H$. pylori infection and the degree of gastric inflammatory activity and gastric H. pylori load. - Helicobacter pylori; stool antigen test; cut-off value; Sydney Grading System; gastritis

(C) 2007 Tohoku University Medical Press

Helicobacter pylori $(H$. pylori) is one of the most common pathogenic microorganisms in human. Fifty percent of the population in developed countries and $80-90 \%$ of the population in developing countries are estimated to carry this pathogen (Rothenbacher et al. 1999). Besides gastritis, $H$. pylori infection has been involved in the pathogenesis of peptic ulcer, gastric adenocarcinoma and lymphoma (Hino et al. 2004). In recent years, noninvasive diagnostic tests used for

Received January 24, 2007; revision accepted for publication April 24, 2007.

Correspondence: Ali K. Adiloglu, Posta Kutusu 61, 32100 Isparta, Turkey.

e-mail: aadiloglu@yahoo.com 
H. pylori infection have gained significance. The Canadian and European consensus conference reports emphasize the importance of these noninvasive diagnostic tests both for diagnosis and post treatment control for children (Sherman et al. 1999; Drumm et al. 2000). Well established noninvasive tests are serology, urea breath test (UBT) and $H$. pylori stool antigen (HpSA) test. Although serological tests are useful in the diagnosis of current $H$. pylori infection, it is not useful for monitoring eradication therapy (De Oliverio et al. 1999; Koletzko and Feydt-Schmidt 2001).

In a meta-analysis, both the ${ }^{13} \mathrm{C}$-UBT and the stool antigen test showed high sensitivity and specificity in adults (Vaira and Vakil 2001). The European Helicobacter Study Group recommended the stool antigen test and the ${ }^{13} \mathrm{C}$-UBT for both diagnosis and assessment of eradication of $H$. pylori infection (Malfertheiner et al. 2002). United States Food and Drug Administration (FDA) approved the stool antigen test for both diagnosing $H$. pylori infection and monitoring eradication efficacy in adults (Vakil et al. 2000). The urea breath test can also be used for both pretreatment examination and post treatment follow-up. However, expensive instrumentation and a specialized technician are required. In addition, the performance of the test has been associated with some disadvantages in infants and very young children as well as in patients with certain neurological disorders. The HpSA test is an important alternative to the UBT (Gramley et al. 1999; Makristathis et al. 2000; Kato et al. 2004). The stool antigen test is recommended for several reasons; stool samples are easily available, and the test is noninvasive and easy to perform. In addition, the accuracy of the test has been confirmed in children. Moreover, this test may be the optimum test to screen and confirm the success of eradication therapy even as early as 2 weeks after the end of therapy (Ni et al. 2000; Oderda et al. 2000).

The HpSA test was also found to be more sensitive and specific than the polymerase chain reaction methods using stool samples (Li et al. 1996; Casswall et al. 1999; McNamara et al. 1999; Makristatis et al. 2000). Polymerase chain reaction of fecal samples can easily yield false negative results because a variety of chemicals in the stool can inhibit the reaction (Wilde et al. 1990; Mapstone and Quirke 1992).

In contrary to the above mentioned studies in favor of HpSA test, commercially available HpSA kits sometimes provide different diagnostic accuracies in different populations and geographical regions (Ohkura et al. 2000). To overcome this problem, in different studies, it was reported that by calculating the cut-off values of HpSA test by receiver operator characteristics (ROC) curve analysis, the sensitivity and specificity of HpSA test increases (Leodolter et al. 2001; Kim et al. 2002; Kato et al. 2003; Syam et al. 2005). Makristatis et al. (2000) also stressed the importance of local test validation especially in post treatment follow-up.

There are only a few reports which emphasize the correlation between gastric inflammation degree and H. pylori load and HpSA optical density (OD) levels (Labenz et al. 1996; Chou et al. 1997; Chang et al. 2002). In regard to the diagnostic tests other that HpSA; C-UBT or urease test either significantly correlated (Labenz et al. 1996; Chou et al. 1997; Chang et al. 2002) or did not correlate (Graham et al. 1987; Logan et al. 1991) with gastric inflammation degree and gastric H. pylori load.

The aim of this study was to determine the cut-off value of the HpSA test to obtain the highest sensitivity and specificity for the diagnosis of $H$. pylori infection in our dyspeptic patients and evaluate the correlation of HpSA OD titers with gastric $H$. pylori load and histological inflammatory activity levels according to updated Sydney System (Dixon et al. 1996).

\section{Materials and Methods}

\section{Patients}

One hundred and thirty-two consecutive patients referred to endoscopy for dyspeptic symptoms lasting longer than 3 months were investigated in the study. Patients who have used proton pump inhibitors, histamine-2 receptor antagonists or bismuth containing compounds in the preceding month, and non-steroidal antiinflammatory drugs in the preceding 15 days before 
endoscopy, patients with abnormal bleeding tests or allergic to anesthetics, pregnant patients, and patients having had gastro-duodenal surgery were excluded. Out of 132 patients, 22 either refused to participate in the study or refused to give feces. Eight patients accepted to participate in the study but were not eligible for the study because of the above mentioned exclusion criteria. Finally a total of 102 patients were included in the study.

Informed consent was obtained from the eligible patients after the nature of the procedure was explained. The study was performed in compliance with humanstudies guidelines and the study has been approved by the Suleyman Demirel University Faculty of Medicine Dean's Office Local Ethical Committee.

During the esophago-gastro-duodenoscopy, biopsy specimens were sampled from both gastric antrum and corpus. Rapid urease test was performed from antrum biopsy samples and microscopic histopathological examinations were performed from both antrum and gastric corpus biopsy samples. H. pylori infection was accepted as positive if both microscopic $H$. pylori detection and urease test of the biopsy specimens were positive and as negative only if both of these tests remained negative and these results were accepted as standard test results. Seven patients were excluded from the study because microscopic $H$. pylori detection and urease results were not both positive or both negative, thus the results of 95 patients were chosen for statistical analysis.

\section{Laboratory analysis}

H. pylori-related histological changes were evaluated by updated Sydney System. Briefly, polymorphonuclear leukocyte (PMNL) density, chronic inflammation (stained by H\&E) and $H$. pylori load (stained by toluidine blue $\mathrm{O}$ ), were scored from 0 to 3 (Dixon et al. 1996; Deveci and Deveci 2004). All specimens were examined by the same experienced pathologist. Patients were asked to collect a specimen from their first stool after endoscopy. Stool samples were divided into aliquots, frozen, and stored $\left(-70^{\circ} \mathrm{C}\right)$ until analysis. Stool samples were analyzed for $H$. pylori antigen using the Premier Platinum HpSA Enzyme Immunoassay (Premier Platinum HpSA, Meridian Diagnostics, Cincinnati, OH, USA). In regard to the manufacturer's cut-off, values greater than or equal to $\mathrm{OD}=0.16$ were considered positive, while those less than 0.14 were considered negative. A value between 0.14 and 0.159 was equivocal. There was no equivocal OD value in our study.
Statistical analysis

Sensitivity, specificity, positive and negative predictive values of HpSA test were calculated by standard methods and evaluated according to the cut-off values recommended by the manufacturer as well as by the best cut-off value calculated by the ROC curve analysis (Swets 1988). The ROC curve analysis was performed by testing different OD values to obtain the highest sensitivity and specificity (Fig. 1). Kendall's tau-b correlation analysis was used to detect the correlations between HpSA OD values, gastric inflammation and $H$. pylori load scores. The graphics were designed as simple scatter graphics with line fit option according to correlation degrees. The statistical analyses were performed using the SPSS for Windows statistical package, version 12.0 (SPSS Inc., Chicago, IL, USA).

\section{Results}

Of the 102 eligible patients, 88 were urease and histology positive, 7 were urease and histology negative, and 7 were histology negative and urease positive or vice versa. The last group was omitted from the statistical evaluation because of conflicting diagnosis of $H$. pylori infection. Finally, a total of 95 patients were eligible for statistical analysis. The mean of ages of the patients was $43.6 \pm 14.2$ ranging from 19 to 73 years. The endoscopic findings of the patients are listed in Table 1. The HpSA test results, obtained using two different cut-off values, recommended by the manufacturer, and calculated by ROC curve analysis, are listed in Table 2. By applying the manufacturer's cut-off value for HpSA test, the sensitivity, specificity, positive and negative predictive values were $51.1 \%, 100 \%$, $100 \%$ and $14.0 \%$, respectively. The best $\mathrm{HpSA}$ cut-off value calculated by the ROC curve analysis was 0.048 (area under the curve: 0.972, asymptotic confidence interval: 0.939-1.004) (Fig. 1 ). With the calculated cut-off value of 0.048 , the sensitivity of the test increased without decreasing the specificity, which was still $100 \%$. Using this cut-off value, 81 of the $88 \mathrm{H}$. pylori positive patients were also HpSA positive $(92.0 \%$ sensitivity), and all of the $7 \mathrm{H}$. pylori negative patients were also HpSA negative (100\% specificity). The positive and negative predictive values of the HpSA test were $100 \%$ and $50.0 \%$, respectively. 
TABLE 1. Endoscopic findings of the patients included.

\begin{tabular}{lccc}
\hline Endoscopic findings & Patients $(n=95)(\%)$ & Hp positive $(\%)$ & Hp negative $(\%)$ \\
\hline Antral or corpus gastritis & $86(90.5)$ & $79(91.9)$ & $7(8.1)$ \\
Duodenitis & $21(22.1)$ & $19(90.5)$ & $2(9.5)$ \\
Gastric ulcer & $2(2.1)$ & $2(100)$ & $0(0)$ \\
Duodenal ulcer & $8(8.4)$ & $8(100)$ & $0(0)$ \\
Gastric and duodenal ulcer & $1(1.1)$ & $1(100)$ & $0(0)$ \\
Esophagitis & $21(22.1)$ & $17(81.0)$ & $4(19.0)$ \\
\hline
\end{tabular}

Hp, Helicobacter pylori.

TABLE 2. HpSA test results according to the cut-off value recommended by the manufacturer as well as by the best cut-off value calculated by the receiver operator characteristics (ROC) curve analysis.

\begin{tabular}{ccccc}
\hline & \multicolumn{2}{c}{$\begin{array}{c}\text { By using manufacturer's } \\
\text { cut-off: } 0.16\end{array}$} & \multicolumn{2}{c}{$\begin{array}{c}\text { By using the best } \\
\text { cut-off: } 0.048\end{array}$} \\
\hline & HpSA (+) & HpSA (-) & HpSA (+) & HpSA (-) \\
\hline H. pylori $(+)$ by standard tests & 45 & 43 & 81 & 7 \\
H. pylori $(-)$ by standard tests & 0 & 7 & 0 & 7 \\
\hline
\end{tabular}

OD, optical density

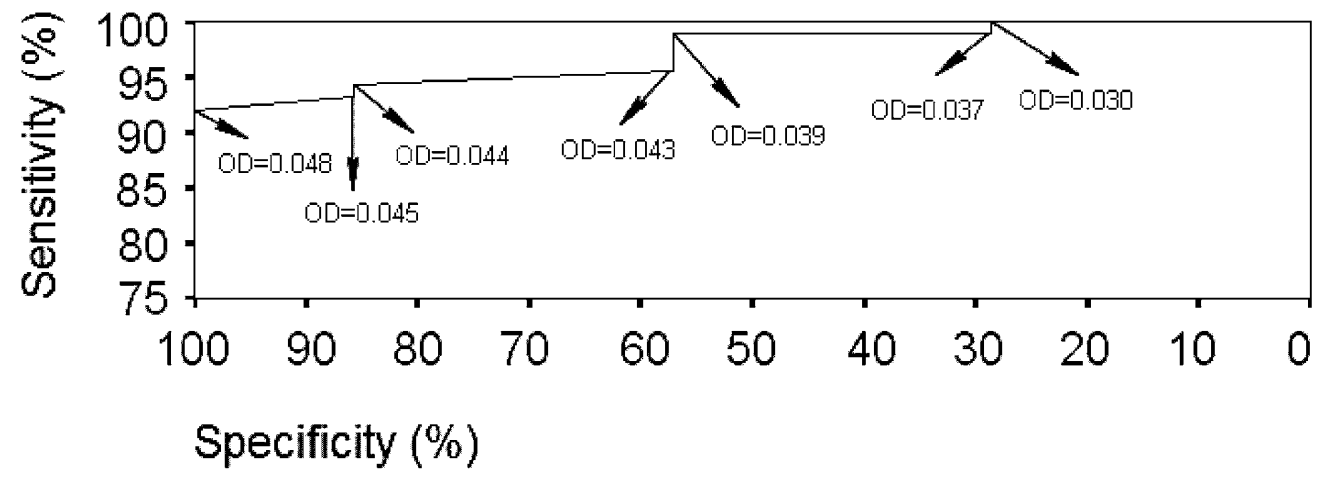

Fig. 1. The receiver operator characteristics (ROC) curve for the detection of best cut-off values of HpSA test. The optimal cut-off value was found to be optical density (OD), 0.048 .

In patients with $H$. pylori infection, the significant correlations of the HpSA OD values with antral inflammation and corpus PMNL density are demonstrated in Figs. 2 and 3, respectively. In addition, gastric antrum PMNL density significantly correlated with HpSA OD values $(r=0.223$, $p=0.005)$. Gastric corpus, but not antrum H. pylori load significantly correlated with $\mathrm{HpSA}$ OD values (Fig. 4).

\section{Discussion}

In previous studies, the HpSA test was investigated for the diagnosis of $H$. pylori infection and the sensitivity and specificity were reported to be over $80 \%$ in symptomatic untreated patients (Makristathis et al. 1998; Puspok et al. 1999; Trevisani et al. 1999; Vaira et al. 1999). In our study, the sensitivity of the HpSA test was found 


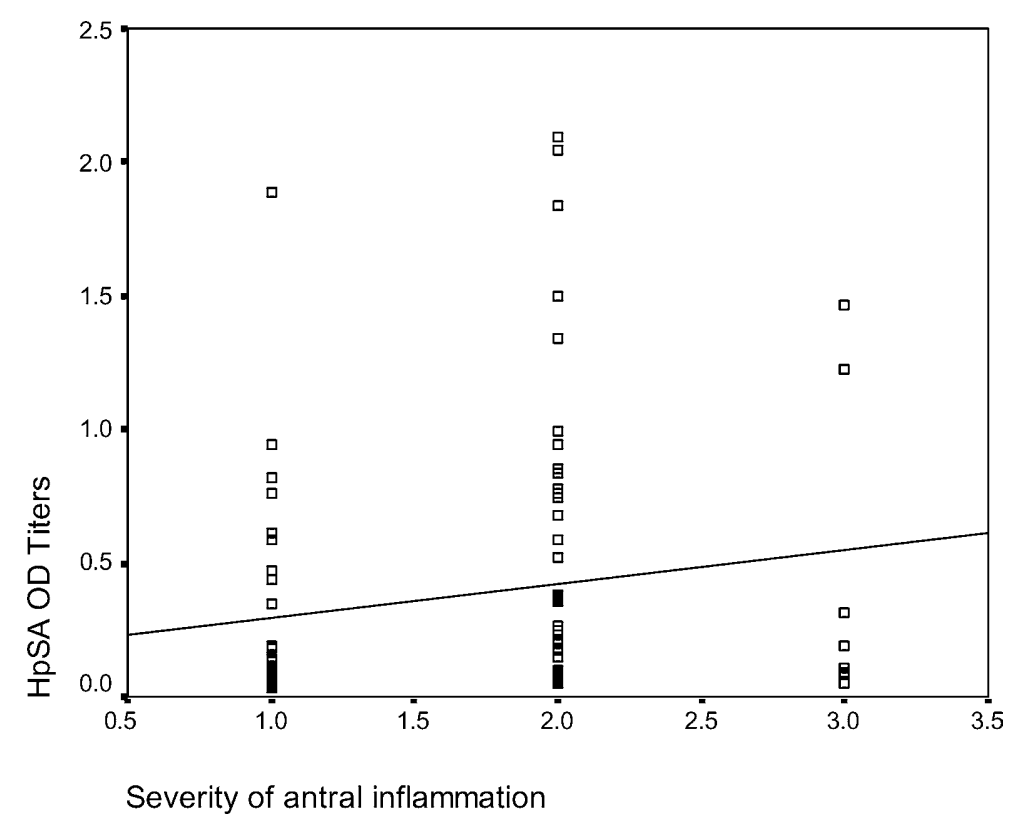

Fig. 2. The significant correlation of the HpSA test optical density (OD) titers with antral inflammation degree $(r=0.217, p=0.011)$.

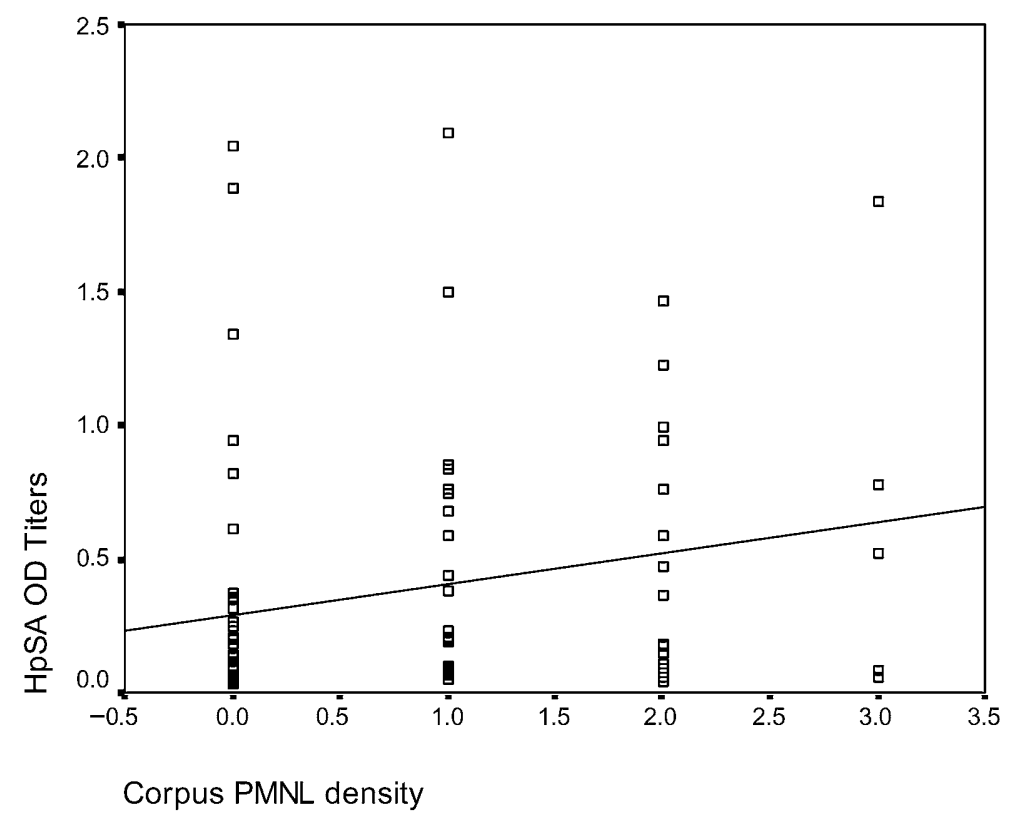

Fig. 3. The significant correlation of the HpSA test optical density (OD) titers with corpus polymorphonuclear leukocytes (PMNL) density $(r=0.222, p=0.007)$.

to be quite low $(51.1 \%)$ when determined on the basis of the manufacturer's cut-off value. However this does not mean that HpSA test does not have high diagnostic accuracy. In fact, according to several reports, HpSA test can be considered reliable in terms of diagnostic accuracy by adjusting the cut-off values for every population separately to obtain the highest sensitivity 


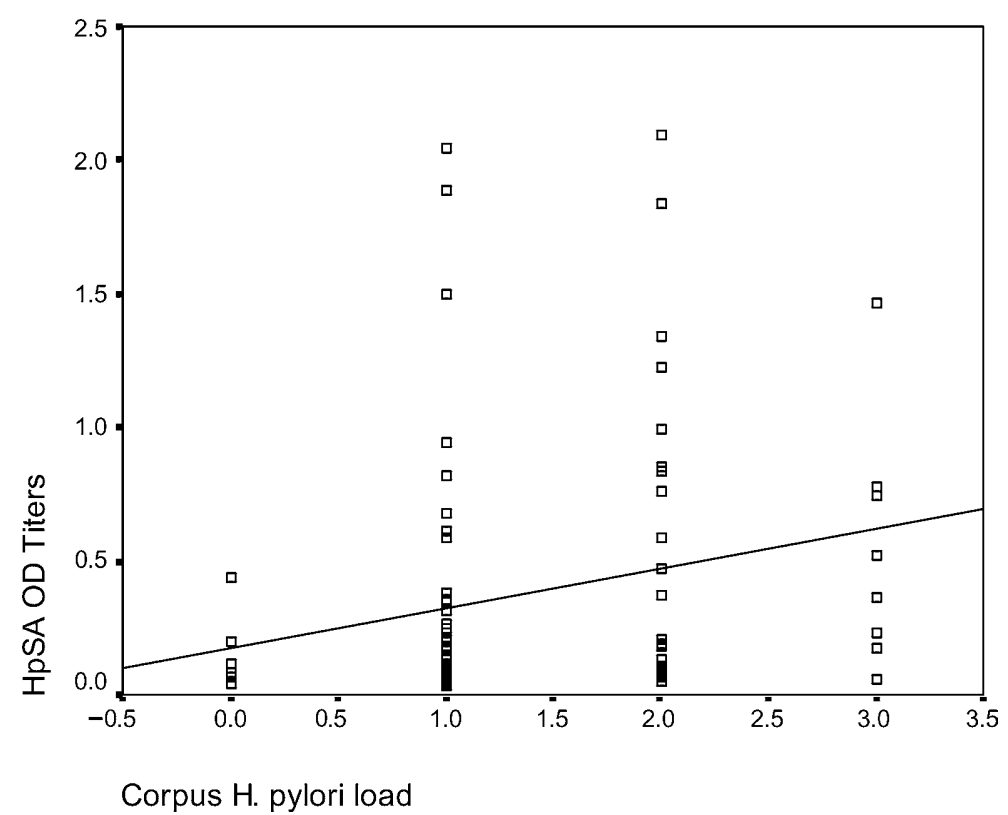

Fig. 4. The significant correlation of the HpSA test optical density (OD) titers with corpus $H$. pylori load $(r=0.239, p=0.004)$.

and specificity. In these studies, the best cut-off values calculated by ROC curve analysis were from OD; 0.024 to 0.3 (Ohkura et al. 2000; Leodolter et al. 2001; Kim et al. 2002; Kato et al. 2003; Syam et al. 2005). In our dyspeptic patients, the best cut-off value calculated by ROC curve analysis was 0.048 and by using this cut-off value, the sensitivity of the test increased from $51.1 \%$ to $92 \%$ without decreasing the specificity of the test.

The feces amount is a variable which may affect the quantitative assessment of the HpSA test. In our region, patients are generally from rural areas who consume meal with higher fiber content when compared with those from urban areas. People living in rural areas consume whole wheat bread made of local flour whereas people living in urban areas consume bread of white flour (bran free) (Aktan et al. 1984). Wisker et al. (1988) stated that the increase in the intake of dietary fiber results in an increase in stool weight. Stevens et al. (1988) also reported that fiber supplementation decreases transit time and increases daily number of defecations and the wet and dry weights of stool. H. pylori may be diluted in the bulky volume of stool in patients who have much more fiber in their diet than western patients (Kamm and Lennard-Jones 1994). This may be one of the reasons for lower number of bacteria in feces which causes lower OD values in $\mathrm{HpSA}$ test.

The best cut-off value may also be related partially to the prevalence of $H$. pylori in the population and $H$. pylori load in the patients' stomach. Syam et al. (2005) investigated the diagnostic accuracy of the HpSA test and detected $100 \%$ sensitivity and $36.8 \%$ specificity using a cut-off value of 0.16 (as recommended by the manufacturer) and $66.7 \%$ sensitivity and $78.9 \%$ specificity using a cut-off value of 0.274 (calculated by ROC curve analysis). In their patient group 6 of 63 (9.5\%) patients were $H$. pylori positive. On the other hand, in another patient group where 31 of $41(75.6 \%)$ patients were $H$. pylori positive, $87.1 \%$ sensitivity and $100 \%$ specificity were detected according to the manufacturer's cut-off value, and $100 \%$ sensitivity and $90 \%$ specificity were detected according to the calculated cut-off value of 0.024 by ROC curve analysis (Kim et al. 2002). These two studies may indicate that in low $H$. pylori prevalent populations the cut-off values of HpSA test are higher whereas in high $H$. pylori 
prevalent populations the cut-off values are lower which is in accordance with our results. The prevalence of $H$. pylori is very high in Turkey. In our region, $H$. pylori infection is endemic. In our previous study conducted in our region, $95.2 \%$ seroprevalence was detected in atherosclerosis patients (Adiloglu et al. 2003). In another serology based Turkish study held in asymptomatic subjects, $30 \%$ of the teenagers and $70 \%$ of the adults already acquire $H$. pylori infection (Us and Hascelik 1998).

In previous studies, the sensitivity and specificity of the HpSA test were found to be comparable to the UBT (Casswall et al. 1999; McNamara et al. 1999; Braden et al. 2000), but there are only a few studies investigating the correlation between HpSA OD values and gastric inflammation scores or $H$. pylori load. The reaction velocity of the biopsy urease test, the $\Delta{ }^{13} \mathrm{C}$ value of the UBT and the OD value of the HpSA test correlated well with $H$. pylori density in the stomach (Labenz et al. 1996; Chou et al. 1997; Chang et al. 2002). In another study, HpSA OD highly correlated with gastric antrum $H$. pylori load evaluated histologically (Gallo et al. 2001). In our study, gastric corpus, but not antrum $H$. pylori load significantly correlated with HpSA OD values (Fig. 4). It was suggested that the UBT can be used to predict both intragastric bacterial load and severity of related gastritis (Perri et al. 1998). However, Matthews et al. (2005) detected that the ${ }^{13} \mathrm{C}$-UBT results significantly correlated with urease and myeloperoxidase activity and severity of gastritis but not with bacterial load. There are also studies which failed to establish a significant correlation between gastric mucosa $H$. pylori load and C-UBT or urease test (Graham et al. 1987; Logan et al. 1991).

To our knowledge there is only one study that investigates the correlation between $\mathrm{HpSA}$ test and gastric inflammation evaluated by updated Sydney System quantitatively. Chang et al. (2002) detected that both the level of $\Delta{ }^{13} \mathrm{CO}_{2}$ of ${ }^{13} \mathrm{C}$-UBT and the OD value of the HpSA test correlated well with the gastric mucosal inflammatory activity diagnosed by updated Sydney System. In our study, antral inflammation degree (Fig. 2), gastric corpus PMNL density (Fig. 3) and antrum PMNL density significantly correlated with $\mathrm{HpSA}$ OD values. The HpSA test is a helpful tool to estimate the severity of gastric inflammatory activity and may predict the need for further invasive procedures. In this point of view, the HpSA test may be an alternative to gastric endoscopy especially in children and some patients who are unable to tolerate endoscopic examination. Moreover, HpSA test may also be an alternative to serological tests for epidemiological researches and it may be used in the screening of asymptomatic individuals who have high risk of gastric malignancies such as young people with a family history of gastric cancer.

In our study, it was found that gastritis scores and bacterial load significantly correlated with HpSA OD values. Denser $H$. pylori infection causes more severe corpus gastritis (Chuang et al. 2004). It is also expected that denser $H$. pylori infection in gastrointestinal tract causes denser antigen in the feces. Matsuda et al. (2003) detected a positive correlation between HpSA OD values and the number of $H$. pylori isolated by quantitative culture of biopsy specimens.

In our study, $H$. pylori negative patients were fewer in number which might seem to be a handicap but the high specificity obtained by HpSA test (100\%), both with the manufacturer's and calculated cut-off values reduced this effect of this handicap.

In conclusion, by adjusting HpSA cut-off values according to our population, the test sensitivity increased without decreasing the specificity. Therefore, the cut-off values of the HpSA test must be calculated for every population separately to obtain the highest sensitivity and specificity. We also concluded that HpSA OD values reflect the severity of gastritis and gastric mucosal $H$. pylori load. As a result, the HpSA test is a helpful tool to evaluate the severity of gastric inflammatory activity and gastric $H$. pylori load and may replace further invasive procedures in some patient groups.

\section{Acknowledgments}

We thank Mrs. Beture Memedova, Associate 
Professor of English Literature in Suleyman Demirel University Faculty of Letters and Sciences, for her assistance in English edition. We also thank Mr. A. Nesimi Kisioglu, Associate Professor of Public Health in Suleyman Demirel University Medical School for his assistance in statistical analysis.

\section{References}

Adiloglu, A.K., Nazli, C., Aridogan, B.C., Kinay, O., Can, R. \& Ergene, O. (2003) Helicobacter pylori and serum CRP coexistence in atherosclerotic and healthy persons. Turkish J. Infect., 17, 405-408. (in Turkish)

Aktan, H., Ozden, A., Kesim, E. \& Smith, A.N. (1984) Colonic function in rural and urban populations of Turkey. Dis Colon Rectum. 27, 538-541.

Braden, B., Posselt, H.G., Ahrens, P., Kitz, R., Dietrich, C.F. \& Caspary, W.F. (2000) New immunoassay in stool provides an accurate noninvasive diagnostic method for Helicobacter pylori screening in children. Pediatrics, 106, 115-117.

Casswall, T.H., Nilsson, H.O., Bergstrom, M., Aleljung, P., Wadstrom. T., Dahlstrom, A.K., Albert, M.J. \& Sarker, S.A. (1999) Evaluation of serology, ${ }^{13}$ C-urea breath-test, and polymerase chain reaction of stool samples to detect Helicobacter pylori in Bangladeshi children. J. Pediatr. Gastroenterol. Nutr., 28, 31-36.

Chang, M.C., Chang, Y.T., Sun, C.T., Wu, M.S., Wang, H.P. \& Lin, J.T. (2002) Quantitative correlation of Helicobacter pylori Stool Antigen test with ${ }^{13} \mathrm{C}$-Urea Breath Test $\left({ }^{13} \mathrm{C}\right.$ UBT) by the Updated Sydney Grading System of Gastritis. Hepatogastroenterology, 49, 576-579.

Chou, C.H., Sheu, B.S., Yang, H.B., Cheng, P.N., Shin, J.S., Chen, C.Y. \& Lin, X.Z. (1997) Clinical assessment of the bacterial load of Helicobacter pylori on gastric mucosa by a new multi-scaled rapid urease test. J. Gastroenterol. Hepatol., 12, 1-6.

Chuang, C.H., Sheu, B.S., Yang, H.B., Kao, A.W., Cheng, H.C. \& Yao, W.J. (2004) Hypergastrinemia after Helicobacter pylori infection is associated with bacterial load and related inflammation of the oxyntic corpus mucosa. J. Gastroenterol. Hepatol., 19, 988-993.

De Oliveria, A.M., Rocha, G.A., Queiroz, D.M., Mendes, E.N., de Carvalho, A.S., Ferrari, T.C. \& Nogueira, A.M. (1999) Evaluation of enzyme linked immunosorbent assay for the diagnosis of Helicobacter pylori infection in children from different age groups with and without duodenal ulcer. $J$. Pediatr. Gastroenterol. Nutr., 28, 157-161.

Deveci, M.S. \& Deveci, G. (2004) Altered distribution of metaplastic paneth, gastrin and pancreatic acinar cells in atrophic gastritic mucosa with endocrine cell lesions. Tohoku J. Exp. Med., 202, 13-22.

Dixon, M.F., Genta, R.M., Yardley, J.H. \& Correa, P. (1996) Classification and grading of gastritis: the updated Sydney System. Am. J. Surg. Pathol., 20, 116.

Drumm, B., Koletzko, S. \& Oderda, G. (2000) On behalf of the European pediatric task force on Helicobacter pylori. Helicobacter pylori infection in children: a consensus statement. J. Pediatr. Gastroenterol. Nutr., 30, 207-213.

Gallo, N., Basso, D., Zambon, C.F., Navaglia, F., Di Mario, F., Rugge, M. \& Plebani, M. (2001) Diagnosis of Helicobacter pylori infection: comparison of techniques. Recenti. Prog. Med., 92, 332-335.
Graham, D.Y., Klein, P.D., Evans, D.J., Evans, D.G., Alpert, L.C., Opekun, A.R. \& Boutton, T.W. (1987) Campylobacter pylori detected noninvasively by the $13 \mathrm{C}$-urea breath test. Lancet, 1, 1174-1177.

Gramley, W.A., Asghar, A., Frierson, H.F. \& Powell, S.M. (1999) Detection of Helicobacter pylori DNA in fecal samples from infected individuals. J. Clin. Microbiol., 37, 2236-2240.

Hino, B., Eliakim, R., Levine, A., Sprecher, H., Berkowitz, D., Hartman, C., Eshach-Adiv, O. \& Shamir, R. (2004) Comparison of invasive and noninvasive tests diagnosis and monitoring of Helicobacter pylori infection in children. $J$. Pediatr. Gastroenterol. Nutr., 39, 519-523.

Kamm, M.A. \& Lennard-Jones, J.E. (1994) Constipation. Hampshire, Wringhtson Biomedical Publishing Ltd., pp. 307-314.

Kato, S., Ozawa, K., Okuda, M., Fujisawa, T, Kagimoto, S., Konno, M., Maisawa, S. \& Linuma, K. (2003) Accuracy of the stool antigen test for the diagnosis of childhood Helicobacter pylori infection. Am. J. Gastroenterol., 98, 296-300.

Kato, S., Nakayama, K., Minoura, T., Konno, M., Tajiri, H., Matsuhisa, T. and Iinuma, K. for the Japanese Pediatric Helicobacter study Group. (2004) Comparison between the 13C-urea breath test and stool antigen test for the diagnosis of childhood Helicobacter pylori infection. J. Gastroenterol., 39, 1045-1050.

Kim, P.S., Lee, J.W., Pai, S.H., Kim, Y.B., Cho, J.K., Lee, J.W., Jeong, S., Lee, D.H., Kim, H.G., Kwon, K.S., Cho, H.G., Shin, Y.W. \& Kim, Y.S. (2002) Detection of Helicobacter pylori antigen in stool by enzyme immunoassay. Yonsei. Med. J., 43, 7-13.

Koletzko, S. \& Feydt-Schmidt, A. (2001) Infants differ from teenagers: use of noninvasive tests for detection of Helicobacter pylori infection in children. Eur. J. Gastroenterol. Hepatol., 13, 1047-1052.

Labenz, J., Barsch, G., Peitz, U., Aygen, S., Hennemann, O., Tillenburg, B., Becker, T. \& Stolte, M. (1996) Validity of a novel biopsy urease test (HUT) and a simplified ${ }^{13} \mathrm{C}$-urea breath test for diagnosis of Helicobacter pylori infection and estimation of the severity of gastritis. Digestion, 57, 391-397.

Leodolter, A., Agha-Amiri, K., Peitz, U., Gerards, C., Ebert, M.P. \& Malfertheiner, P. (2001) Validity of Helicobacter pylori stool antigen assay for the assessment of Helicobacter pylori status following eradication therapy. Eur. J. Gastroenterol. Hepatol., 13, 673-676.

Li, C., Ha, T., Ferguson, D.A., Chi, D.S., Zhao, R., Patel, N.R., Krishnaswamy, G. \& Thomas, E. (1996) A newly developed PCR assay of Helicobacter pylori in gastric biopsy, saliva, and feces. Evidence of high prevalence of Helicobacter pylori in saliva supports oral transmission. Dig. Dis. Sci., 41, 2142-2149.

Logan, R.P.H., Polson, R.J., Misiewics, J.J., Rao, G., Karim Q.N., Newell, D., Johnson, P., Wadsworth J., Walker, M.M. \& Baron, J.H. (1991) Simplified single sample ${ }^{13} \mathrm{C}$-urea breath test for Helicobacter pylori: comparison with histology, culture and ELISA serology. Gut, 32, 1461-1464.

Makristathis, A., Pasching, E., Schutze, K., Wimmer, M., Rotter, M.L. \& Hirschl, A.M. (1998) Detection of Helicobacter pylori in stool specimens by PCR and antigen enzyme immunoassay. J. Clin. Microbiol., 36, 2772-2774.

Makristathis, A., Barousch, W., Pasching, E., Binder, C., Kuderna, C., Apfalter, P., Rotter, M.L. \& Hirschl, A.M. 
(2000) Two enzyme immunoassays and PCR for detection of Helicobacter pylori in stool specimens from pediatric patients before and after eradication therapy. J. Clin. Microbiol., 38, 3710-3714.

Malfertheiner, P., Megraud, F., O’Morian, C., Hungin, A.P.S., Jones, R., Axon, A., Graham, D.Y., Tytgat, G. \& European Helicobacter pylori Study Group (EHPSG) (2002) Current concepts in the management of Helicobacter pylori infection-the Maastricht 2-2000 Consensus Report. Aliment. Pharmacol. Ther., 16, 167-180.

Mapstone, N.P. \& Quirke, P. (1992) Molecular biology and infections of the gut. Gut, 33, 1441-1443.

Matsuda, M., Noda, Y. \& Takemori, Y. (2003) Utility and limitations of a method for detecting Helicobacter pylorispecific antigens in the stool. J. Gastroenterol., 38, 222-228.

Matthews, G.M., Cummins, A.G., Lawrence, A., Johnson, B., Campbell, F. \& Butler, R.N. (2005) ${ }^{13}$ C-urea breath test: reproducibility and association with the severity of Helicobacter pylori-associated antral gastritis. J. Gastroenterol. Hepatol., 20, 270-274.

McNamara, D., Whelan, H., Hamilton, H., Beattie, S. \& O'Morain, C. (1999) HpSA: assessment ofa new noninvasive diagnostic assay for Helicobacter pylori infec-tion in an Irish population. Ir. J. Med. Sci., 168, 111-113.

Ni, Y.H., Lin, J.T., Huang, S.F., Yang, J.C. \& Chang, M.H. (2000) Accurate diagnosis of Helicobacter pylori infection by stool antigen test and 6 other currently available tests in children. J. Pediatr., 136, 714-716.

Oderda, G., Rapa, A., Ronchi, B., Lerro, P., Pastore, M., Staiano, A., de'Angelis, G.L. \& Strisciuglio, P. (2000) Detection of Helicobacter pylori in stool specimens by non-invasive antigen enzyme immu-noassay in children: multicentre Italian study. $B M J, \mathbf{3 2 0}, 347-348$.

Ohkura, R., Miwa, H., Murai, T., Nagahara, A., Ohta, K., Sato, K., Yamada, T. \& Sato, N. (2000) usefulness of a novel immunoassay foe the detection of Helicobacter pylori in feces. Scand. J. Gastroenterol., 35, 49-53.

Perri, F., Clemente, R., Pastore, M., Quitadamo, M., Festa, V., Bisceglia, M., Li Bergoli, M., Lauriola, G., Leandro, G., Ghoos, Y., Rutgeerts, P. \& Andriulli, A. (1998) The ${ }^{13} \mathrm{C}$ urea breath test as a predictor of intragastric bacterial load and severity of Helicobacter pylori gastritis. Scand. J. Clin. Lab. Invest., 58, 19-27.

Puspok, A., Bakos, S. \& Oberhuber, G. (1999) A new noninvasive method for detection of Helicobacter pylori: Validity in the routine clinical setting. Eur. J. Gastroenterol. Hepa- tol., 11, 1139-1142.

Rothenbacher, D., Inceoglu, J., Bode, G. \& Brenner, H. (1999) Helicobacter pylori infection in asymptomatic infants: population based study suggests that infection occurs within the first two years of life. Gut, 45, Suppl. 3, 125-130.

Sherman, P., Hassal, E., Hunt, H., Fallone, A., Veldhuyzen van Zanten, S., Thomson, A.B.R. \& the Canadian Helicobacter study group (1999) Canadian Helicobacter Study Group Consensus Conference on the Approach to Helicobacter pylori Infection in Children and Adolescents. Can. J. Gastroenterol., 13, 553-559.

Stevens, J., VanSoest, P.J., Robertson, J.B. \& Levitsky, D.A. (1988) Comparison of the effects of psyllium and wheat bran on gastrointestinal transit time and stool characteristics. J. Am. Diet. Assoc., 88, 323-326.

Swets, J.A. (1988) Measuring the accuracy of diagnostic systems. Science, 240, 1285-1293.

Syam, A.F., Rani, A.A., Abdullah, M., Manan, C., Makmun, D., Simadibrata, M., Djojoningrat, D. \& Sato, T. (2005) Accuracy of Helicobacter pylori stool antigen for the detection of Helicobacter pylori infection in dyspeptic patients. World J. Gastroenterol., 11, 386-388.

Trevisani, L., Sartori, S., Galvani, F., Rossi, M.R., Ruina, M., Chiamenti, C. \& Caselli, M. (1999) Evaluation of a new enzyme immunoassay for detecting Helicobacter pylori in feces: a prospective pilot study. Am. J. Gastroenterol., 94, 1830-1833.

Us, D. \& Hascelik, G. (1998) Seroprevalence of Helicobacter pylori infection in an asymptomatic Turkish population. $J$. Infect., 37, 148-150.

Vaira, D., Malfertheiner, P., Megraud, F. \& Axon, A.T. (1999) Diagnosis of Helicobacter pylori infection by HpSA test. European Helicobacter pylori HpSA study group. Lancet, 354, 30-33.

Vaira, D. \& Vakil, N. (2001) Blood, urine, stool, breath, money, and Helicobacter pylori. Gut, 48, 287-289.

Vakil, N. \& Affi, A. Robinson, J., Sundaram, M. \& Phadnis, S. (2000) Prospective blinded trial of a fecal antigen test for the detection of Helicobacter pylori infection. Am. J. Gastroenterol., 95, 1699-1701.

Wilde, J., Eiden, J. \& Yolken, R. (1990) Removal of inhibitory substances from fecal specimens for detection of group A rotaviruses by reverse transcriptase and polymerase chain reactions. J. Clin. Microbiol., 28, 1300-1307.

Wisker, E., Maltz, A. \& Feldheim, W. (1988) Metabolizable energy of diets low or high in dietary fiber from cereals when eaten by human. J. Nutr., 118, 945-952. 